\title{
To the Editor; A Commentary on "Switching From Originator to Biosimilar Human Growth Hormone Using a Dialogue Teamwork: Single-Center Experience From Sweden"
}

\author{
Mats Ekelund $\cdot$ Christopher Bidad $\cdot$ Roy Gomez
}

To view enhanced content go to www.biologicstherapy-open.com

Received: January 15, 2014 / Published online: April 23, 2014

(c) The Author(s) 2014. This article is published with open access at Springerlink.com

To the Editor

The manuscript by Flodmark et al. [1] recently published in the open-access journal Biologics in Therapy describes a single-center experience in Sweden of a switch from an originator biologic to a biosimilar human growth hormone (rhGH) using a dialogue teamwork approach [1]. Unfortunately, the authors fail to mention several limitations to their study which call into question their conclusions.

To evaluate the effect on growth of switching from originator to biosimilar rhGH, Flodmark et al. [2] applied a modeling approach previously developed based on limited Phase 3

Mats Ekelund no longer works at Pfizer, but this was his affiliation at time of writing.

Electronic supplementary material The online version of this article (doi:10.1007/s13554-014-0015-3) contains supplementary material, which is available to authorized users.

M. Ekelund

Pfizer AB, Stockholm, Sweden

C. Bidad $(\bowtie)$

Pfizer Ltd, Tadworth, UK

e-mail: christopher.bidad@pfizer.com

R. Gomez

Pfizer, Brussels, Belgium clinical trial data. However, there are several questions regarding the suitability of this modeling approach and the methods used to compare the effect of originator and biosimilar rhGH on growth. First, it is unclear from either the current or the previously published manuscript whether the applied model has been suitably validated using an appropriate study population, with adequate sample sizes and suitable treatment duration. In this regard, the analysis described by the authors in their current report appears to be one of prediction model assessment, rather than treatment comparison. Second, given the heterogeneity in the diagnoses and pubertal status of the population treated with growth hormone, it is not clear whether the same prediction model would be appropriate for the different patient or diagnostic groups included in the current analysis (see, e.g., Ranke et al. [3]. Third, treatment history is not addressed by the applied model, an important issue given that prior treatment duration and history would be expected to affect growth performance. Fourth, the model employed by the authors [2] was derived from a small number of patients treated with originator rhGH for only 9 months, 
whereas Flodmark et al. use the same model to make predictions over a 3-year period; the validity of this extrapolation has not been justified. It is also unclear how repeated measures for each individual patient were addressed, given that these affect the reporting of coefficient of determination $\left(R^{2}\right)$ and standard deviation (SD) and can lead to spurious results. Finally, the reported age range of subjects (1-15 years) included in the manuscript by Flodmark et al. suggests that some subjects may have been at the tail end of their growth trajectory prior to switching rhGH products and had limited anticipated growth following the switch.

The manuscript by Flodmark et al. states that there were no reports of serious or unexpected adverse drug reactions (ADRs) following the switch to biosimilar rhGH. It is not clear from the report how the distinction between unexpected and expected ADRs was operationalized. However, they also state that 19 ADRs (18 pain at injection site and 1 pitting edema) were reported in 18 patients. A discussion about this rate is wanting. Is the switch exposing patients to a higher rate of ADRs than they would have experienced without the switch? Is the rate comparable to or higher than the rate normally observed when patients start a new treatment? To illustrate the relevance of the latter question, a comparison was made between the rate of ADRs in this report with the rate observed in a prospective clinical study that compared ease of use and preference for a new disposable rhGH injection pen relative to previous experience with the currently available reusable pen in standard practice. Hey-Hadavi et al. [4] reported 8 devicerelated ADRs in 7 out of 137 subjects $(5.1 \%$; injection-site hematoma in 3 and injection-site pain in 5) compared to 18 cases in 98 patients (18.4\%) reported by Flodmark et al. Although, one should be very cautious about drawing conclusions from a side by side comparison of ADRs between two studies, where the methods to collect and register the ADRs as well as the definitions of ADRs may have differed, there are no reasons to expect that study of Hey-Hadavi would systematically underestimate the number of injection-site-related ADRs compared to Flodmark study.

Flodmark et al. suggest that the switch to biosimilar rhGH was acceptable to patients since 98 of the 102 offered the switch agreed. Later in the paper, the authors comment that the switch of device types is not necessary without a consequence in that "switching to a different rhGH product also involves the use of a new injection device. Consequently, patients must learn, and get used to, a different injection technique". Previous studies of ease of use of injection devices [4] suggest that not all devices are similar in ease of use. In addition, as pointed out by Grimberg et al. [5], both clinic costs and non-compliance risks associated with switching are not inconsequential. Flodmark et al. included neither in their assessment of outcome.

This oversight is complicated by a failure of the authors to address the cost of switching when calculating the economic benefit of the switch incurred due to differences in product cost. One would expect that all costs and benefits be considered in a rigorous economic analysis. Finally, the authors report that patients were given a choice of switching to biosimilar rhGH or paying for the difference in cost between their own product and the biosimilar. Since the originator biologic was reimbursed by the government it is not clear on what grounds the clinic could have charged the patients and indeed four patients were allowed to continue without contributing to the cost of therapy. 
These limitations, together with a lack of a cautionary note on the danger of overinterpretation of the result from this noninterventional study, raise questions regarding the validity of the study and its conclusions.

\section{ACKNOWLEDGMENTS}

Article processing charges for this commentary were funded by Pfizer. All named authors meet the ICMJE criteria for authorship for this manuscript, take responsibility for the integrity of the work as a whole, and have given final approval for the version to be published.

Conflict of interest. At time of writing Mats Ekelund was an employee of Pfizer.

Christopher Bidad is an employee of Pfizer. Roy Gomez is an employee of Pfizer.

Compliance with ethics. The content of this commentary is based on previously conducted studies, and does not involve any new studies of human or animal subjects performed by any of the authors.

Open Access. This article is distributed under the terms of the Creative Commons Attribution Noncommercial License which permits any noncommercial use, distribution, and reproduction in any medium, provided the original author(s) and the source are credited.

\section{REFERENCES}

1. Flodmark C-E, Lilja K, Woehling H, Järvholm K. Switching from originator to biosimilar human growth hormone using dialogue teamwork: singlecenter experience from Sweden. Biol Ther. 2013;3: 35-43.

2. Romer T, Zabransky M, Walczak M, Szalecki M, Balser S. Effect of switching recombinant human growth hormone: comparative analysis of phase 3 clinical data. Biol Ther. 2011;1:1-14.

3. Ranke MB, Lindberg A, KIGS International Board. Observed and predicted growth responses in prepubertal children with growth disorders: guidance of growth hormone treatment by empirical variables. J Clin Endocrinol Metab. 2010;95(3):1229-37.

4. Hey-Hadavi J, Pleil A, Deeb LC, Fuqua JS, Silverman LA, Reiner B, Newfield R, Rajicic N, Wajrnrajch MP, Cara JF. Ease of use and preference for a new disposable self-injection pen compared with a reusable pen for administering recombinant human growth hormone: a multicenter, 2-month, singlearm, open-label clinical trial in patient-caregiver dyads. Clin Ther. 2010;32(12):2036-47.

5. Grimberg A, Feudtner C, Gordon CM. Consequences of brand switches during the course of pediatric growth hormone treatment. Endocr Pract. 2012; 18:307-16. 